\title{
Memes Nego - o discurso racista (des)velado na composição multimodal
}

\author{
Ailton Pinheiro MOREIRA (D) \\ Universidade Estadual do Ceará (UECE)
}

Ana Maria Pereira LIMA (D)

OPEN ACCESS

Universidade Estadual do Ceará (UECE)

EDITADO POR

- Raquel Freitag (UFS)

AVALIADO POR

- Hélio Oliveira (UNICAMP)

- Andréa P. S. Aguiar (PUC-SP)

SOBRE OS AUTORES

- Ailton Pinheiro Moreira

Conceptualização,

Investigação, Escrita - análise e edição.

- Ana Maria Pereira Lima

Supervisão, Escrita - análise e edição.

- José Ribamar L. Batista Júnior Metodologia, Escrita - análise e edição.

DATAS

- Recebido: 10/08/2021

- Aceito: 23/11/2021

- Publicado: 14/12/2021

\section{COMO CITAR}

Moreira, A. P.; Lima, A. M. P.: Batista Júnior, J. R. L. (2021) Memes Nego - o discurso racista (des) velado na composição multimodal. Revista da Abralin, v. 20, n. 2, p. 1-24, José Ribamar Lopes BATISTA JÚNIOR (D) Universidade Federal do Piaui (UFPI)

\section{RESUMO}

Ante as transformações profundas por que tem passado a sociedade atual, em grande parte, devido às tecnologias digitais e à internet, as práticas discursivas se intensificam e promovem a recontextualização de gêneros e artefatos culturais marcados pela multimodalidade, materializando discursos proferidos por forças hegemônicas que se apoiam em ideologias para sustentar-se e fortalecer relações assimétricas de poder. O racismo encontra suporte nessas práticas discursivas e segue posicionando-se, muitas vezes, de maneira velada, e isso requer dos interactantes uma leitura/observação atenta dos textos com que interagem. Memes de internet, pretensamente jocosos, podem atuar a serviço dessas ideologias, naturalizando o racismo. Assim, os Memes Nego são escopo dessa pesquisa descritivo-qualitativa, que objetiva refletir sobre o racismo (des)velado em sua composição multimodal, avaliar seu teor "jocoso", provocar o pensamento crítico-reflexivo e contribuir com a discussão sobre o racismo no Brasil sob a ótica da Análise de Discurso Crítica (FAIRCLOUGH, 2001; 2003; RESENDE; RAMALHO, 2019; VIEIRA; RESENDE, 2016). As análises revelaram que a ideologia racista ancora-se no teor pretensamente jocoso desses memes e busca naturalizar assimetrias de poder e fortalecer estruturas sociais marcadas pela exclusão e pela exploração de pessoas negras. 


\section{REVISTA DA ABRALIN}

\section{ABSTRACT}

In the face of the profound changes that today's society has undergone, largely due to digital technologies and the internet, discursive practices intensify and promote the recontextualization of genres and cultural artifacts marked by multimodality materializing speeches by hegemonic groups that rely on ideologies to support themselves and strengthen asymmetric power relations. Racism finds support in discursive practices and continues to position itself, often in a veiled way, and this requires interactants to carefully read/observe the texts with which they interact. Internet memes, supposedly jesting, may act in service of these ideologies by naturalizing racism. Thus, Nego Memes are the scope of this descriptive-qualitative research, aiming to reflect on racism (un)revealed in its multimodal composition, to assess its "joking" content, to induce the critical thinking, and to reinforce the discussion focused on racism in Brazil from the perspective of Critical Discourse Analysis (FAIRCLOUGH, 2001; 2003; RESENDE; RAMALHO, 2019; VIEIRA; RESENDE, 2016). The analysis revealed that the racist ideology finds support in the supposedly jesting content of these memes, naturalizing asymmetries of power and strengthening social structures marked by the exclusion and exploitation of black people.

\section{PALAVRAS-CHAVE}

Memes. Racismo. Multimodalidade. Análise de Discurso Crítica.

\section{KEYWORDS}

Memes. Racism. Multimodality. Critical Discourse Analysis.

\section{Introdução}

A revolução tecnológica tem causado mudanças profundas na maneira como nos comunicamos especialmente através das tecnologias digitais conectadas à internet. Enquanto as interações virtuais se intensificam, é imprescindível que se atente não apenas para as condições de acesso aos conteúdos consumidos e compartilhados nos meios digitais, mas também para seu processamento, suas formas de apreensão e sua influência nos modos particulares de significar o mundo. Essa mudança de postura requer o desenvolvimento do senso crítico-reflexivo dos indivíduos para que se possa 


\section{REVISTA DA ABRALIN}

abstrair o que subjaz aos gêneros discursivos e demais artefatos culturais carregados de ideologias ${ }^{1}$ propagadas na rede.

Assim, as interações virtuais propiciam a proliferação de uma miríade heterogênea e multifacetada de textos, mobilizados por discursos proferidos por coletivos sociais particulares, atuando na representação de aspectos do mundo sob a égide de grupos hegemônicos empenhados em legitimar e consolidar o status quo que lhes confere privilégios ao mesmo tempo em que contribuem para a naturalização do ethos da sociedade hodierna ainda bastante indiferente a posicionamentos críticoreflexivos, mesmo quando ancorados em constatações factuais e científicas, que possam causar tensões e transformar esse seu estado atual.

Permeando as interações virtuais, estão inúmeros recursos dos quais se valem os indivíduos para materializar aspectos do mundo e dar concretude aos discursos. Recursos como os memes verboimagéticos (CHAGAS, 2020), artefatos culturais híbridos, proliferados intensamente pela rede, figuram entre as possibilidades mais recorrentes em situações dialógicas. Esses memes, que não são um produto cultural recente, resultam de práticas socioculturais relativamente novas arquitetadas por internautas por meio dos elementos de que dispõem em seus contextos específicos (LIMA-NETO, 2020).

Os memes verbo-imagéticos, textos multimodais, atuam como espaços pelos quais se materializam crenças, valores, atitudes e ideologias supremacistas e excludentes. É essencial, pois, que intensifiquemos os debates sobre a necessidade e a urgência do despertar do senso crítico-reflexivo por parte daquelas/es engajadas/os no ato comunicacional para desvelar relações assimétricas de poder nas instituições e nas relações sociodiscursivas. Sob essa ótica, é premente que atentemos ao racismo no Brasil, para discuti-lo e reconhecê-lo como estrutural e, a partir disso, possamos combater o projeto de naturalização do suposto "racismo reverso", avidamente defendido por pensamentos e posicionamentos eurocêntricos que se valem das mídias de massa (entre outros recursos) em que "reality" shows de natureza questionável têm desdobramentos sobre as vidas de pessoas negras, muitas vezes, consideradas com base em posicionamentos subjetivos e de senso crítico pouco desenvolvido.

Não obstante o vasto cabedal de aportes teóricos e metodológicos existentes para aprofundar esse debate, optamos por aqueles que julgamos mais pertinentes à consecução dos objetivos que nos instigam ao estudo ora proposto. Entre eles, destacamos as contribuições dos estudos da multimodalidade, que versam sobre a (des)centralização da escrita em relação a outros elementos para produção de significados (JEWITT, 2014) para propor um olhar mais crítico sobre os recursos multissemióticos e suas articulações em práticas discursivas diversas que veiculam significados e que podem (des)velar posicionamentos hegemônicos.

Outrossim, recorremos às contribuições da Análise de Discurso Crítica (doravante, ADC) (FAIRCLOUGH, 2001; 2003; RESENDE; RAMALHO, 2019; VIEIRA; RESENDE, 2016), consubstanciada pela

\footnotetext{
${ }^{1}$ Referimo-nos a ideologia, aqui, em sentido inerentemente negativo, instrumento semiótico de lutas de poder; uma maneira pela qual se assegura temporariamente a hegemonia pela propagação de uma representação particular do mundo tomada como a única possível e legítima; desvelar as ideologias é o primeiro passo para a superação das relações assimétricas de poder (VIEIRA; RESENDE, 2016. p. 27).
} 


\section{REVISTA DA ABRALIN}

Linguística Sistêmico Funcional (a partir daqui, LSF) (HALLIDAY, 1978), arcabouços teórico-metodológicos que possam elucidar ainda mais as questões em pauta e contribuir, assim, para uma mudança nas práticas sociais que possam tensionar as estruturas da sociedade, tendo como efeito de causa a mudança social.

Desta feita, objetivamos com este estudo refletir sobre o racismo (des)velado nos memes Nego na perspectiva do significado representacional proposto pela ADC; avaliar o teor "jocoso" atribuído a esse coletivo de memes com vistas à reflexão sobre o que, de fato, subjaz ao discurso materializado na composição multimodal do corpus coletado, lançar luz sobre a relevância do despertar do pensamento crítico-reflexivo e contribuir para as discussões acerca do racismo estrutural no Brasil ante a multimodalidade dos memes Nego.

Optamos por esses memes devido à sua popularidade e à sua circulação nas redes sociais e, especialmente, em razão da constituição dos discursos proferidos que abordam crenças, atitudes e valores alinhados à ideologia racista. Somado a esse fato, esse debate se faz imprescindível ante as estatísticas que indicam serem as pessoas negras as maiores vítimas de opressões, explorações e restrições no Brasil, onde se debatem contra uma média salarial inferior àquela das pessoas brancas, o aumento crescente nos crimes de feminicídio de negras, a juventude negra que segue sendo a mais visada para a morte, o fato de mais de $60 \%$ da população carcerária ser formada por negros e pardos, a baixa representatividade de pessoas negras nas artes e na ciência, e os acirrados debates suscitados por posturas negacionistas relutantes em enxergar o racismo como elemento estrutural no intricado tecido social do Brasil.

Este artigo está organizado nas seguintes seções, além desta introdução e da conclusão: 1) Linguística Sistêmico-Funcional e Multimodalidade: iniciamos com uma breve reflexão sobre a LSF e a Multimodalidade para enfatizar sua relevância para a concepção da relação dialética e da indissociabilidade entre a linguagem e a sociedade/contexto, corroborar a pertinência da abordagem dos memes em seu aspecto multimodal, materializando discursos na internet; 2) Análise de Discurso Crítica (ADC): recorremos aos estudos da linguagem amparados na ADC com foco em seu potencial teórico-prático para o desvelamento de ideologias no discurso; 3) Memes de internet: aprofundamos os debates acerca dos memes, que são artefatos culturais verbo-imagéticos com potencial de (re)produção de significados; 4) Procedimentos metodológicos: uma breve descrição dos métodos analíticos com que abordamos o corpus selecionado; 5) Análise de corpus: por conseguinte, as análises do corpus no intuito de atingir os objetivos propostos; 6) Considerações finais: na conclusão, apresentamos as considerações finais.

\section{Linguística Sistêmico-Funcional e Multimodalidade}

Ao compreender a comunicação enquanto prática social em que produzimos sentidos, A LSF de Halliday (1978) reforça a concepção da língua enquanto semiose social não restrita à mente do indivíduo, mas que perpassa as práticas sociais e atende a objetivos interacionais sócio-historicamente situados 


\section{REVISTA DA ABRALIN}

e desempenha funções em determinados contextos socioculturais. Nesse sentido, para se conceber a língua em sua totalidade, há que se considerar o contexto social em que ela opera (MARTINS, 2018).

A LSF postula a indissociabilidade entre o sujeito e o contexto. Nessa esteira de pensamento, não apenas o contexto, mas também as crenças, as atitudes, as ideologias e as funções sociais exercem profunda influência sobre os sujeitos envolvidos no ato comunicativo. Essa perspectiva sistêmico-funcional propõe três metafunções da linguagem, a saber: 1) ideacional (de natureza representacional, manifestação da consciência humana); 2) interpessoal (capacidade de persuasão, interpretação dos pensamentos dos interactantes); e 3) textual (organização dos significados ideacionais e interpessoais, materializando os discursos) (GOUVEIA, 2009)2.

Balizada por estudos da semiótica social, Pinheiro (2016, p. 25) ressalta as "análises políticas, historicizadas e críticas, pois os autores investigam os 'passos' teórico-metodológicos de produtores e interpretantes dos textos a partir das suas escolhas e interesses". Influenciados por esses estudos, Hodge e Kress (1988) passam a considerar não apenas a linguagem verbal nas interações, abarcam, também, outros modos semióticos para a produção de sentido e chamam a atenção para o fato de que os processos estruturantes da linguagem só podem ser depreendidos quando considerada a dimensão social. Isso implica na possibilidade de se desenvolver um estudo sistemático, compreensivo e coerente e que considere a comunicação como um todo social, cultural e histórico permeado por ideologias e marcado por relações de poder.

Os autores supracitados, em Arruda (2017, p. 19), enfatizam, ainda, os procedimentos e efeitos de produção, consumo e disseminação de significados por indivíduos engajados no ato comunicativo em que entram em cena princípios semióticos amplos como: "1) a noção de escolha do sistema de linguagem; 2) as configurações de significado a partir do contexto; e 3) as funções semióticas da linguagem" que compreendem princípios fundamentais da teoria da multimodalidade discursiva.

Ante o exposto, enfatizamos a problematização das práticas discursivas em que sujeitos se engajam para significar o mundo (e a si mesmos) como um todo pluricultural marcado por assimetrias de poder em que indivíduos pertencentes a determinadas estruturas sociais posicionam-se em defesa de privilégios e do fortalecimento de opressões que subjugam outros indivíduos.

Urge, portanto, que reflitamos sobre um dos aspectos mais marcantes da comunicação humana: a multimodalidade, que não é uma inovação da sociedade atual, posto que já era recurso evidente em gêneros ${ }^{3}$ discursivos de sociedades antigas em contextos sócio-históricos e culturais bastante diversos e cronologicamente distantes. Nesse sentido, deve ser compreendida enquanto uma questão antiga, mas que foi recontextualizada, mesclando modos semióticos múltiplos (como, por exemplo, o som, a imagem, o vídeo, o texto verbal, marcas tipográficas, layout...) para construir significado

\footnotetext{
${ }^{2}$ Esse aporte teórico veio a subsidiar a ADC, foco de nossas atenções nas seções subsequentes.

3 "Gêneros são formas de vida, modos de ser. São frames para a ação social. São ambientes para a aprendizagem. São os lugares onde o sentido é construído. Os gêneros moldam os pensamentos que formamos e as comunicações através das quais interagimos. Gêneros são os lugares familiares para onde nos dirigimos para criar ações comunicativas inteligíveis uns com os outros e são os modelos que utilizamos para explorar o não-familiar" (BAZERMAN, 2006, p.23).
} 


\section{REVISTA DA ABRALIN}

e anteder às demandas da sociedade atual profundamente transformada pelas tecnologias digitais (ARRUDA, 2017).

Na profusão de interações digitalizadas (em especial, na internet), é imprescindível que reflitamos sobre a democratização dos possíveis espaços discursivos em que significados são produzidos, consumidos e propagados de maneira bastante irrestrita, muitas vezes, à revelia dos termos de uso impostos pelas redes sociais, que são espaços intensamente visitados e utilizados em uma relação dialética para a concretização desses discursos nem sempre afeitos aos direitos humanos, à inclusão, à tolerância e à multiculturalidade.

Recorremos às contribuições de Jewitt (2014) para refletir sobre quatro pressupostos teóricos basilares da multimodalidade. O primeiro pressuposto ocupa-se da centralidade do texto verbal enquanto produtor de sentido, especialmente em instituições como a educação. Isso implica que a multimodalidade não prescinde do texto verbal, mas consubstancia-se dele considerando que, no ato comunicativo, as representações de aspectos do mundo assuem muitas formas, constituem-se de diversos recursos para se materializar. A partir dessa ótica, consideramos que as produções de textos não verbais são uma realidade que os memes ajudam a consolidar e, assim, descentram a relevância ou sobreposição da escrita sobre as outras formas.

O segundo pressuposto está relacionado às funções sociais desempenhadas pelo todo multimodal discursivo situado em contextos sociais, culturais e históricos específicos, e atendem às intenções, às necessidades e aos desejos de suas/seus interactantes. Os memes, nesse contexto, não são empregados de maneira descomprometida; atuam na consecução de funções sociais diversas e relativamente variáveis a depender dos elementos inerentes aos contextos em que são produzidos, compartilhados, consumidos e replicados.

No tocante ao terceiro pressuposto, a autora chama atenção para as escolhas dos modos de significação e sua orquestração por parte dos indivíduos, uma vez que há uma relação dialógica entre esses modos que em muito pode contribuir para o (des)velamento dos sentidos inerentes ao texto multimodal. Relações intertextuais, sobreposição de elementos constitutivos dos memes, seleção de saliências e tons, de recursos lexicográficos precisam ser consideradas nesse panorama.

E, finalmente, o quarto pressuposto recai sobre o fato de que os sentidos dos signos têm natureza social, isto é, assim como o discurso, são materializados por meio de recursos multissemióticos que atendem a normas e regras atuantes na mobilização desses signos sob a influência das motivações de suas/seus criadoras/es em contextos sociais específicos. Consideramos, nesse sentido, elementos como por quem, para quem, onde, quando, por que se recorreu ao meme como recurso para transmitir sentidos.

Na sociedade contemporânea, em que culturas se atravessam na e pela cibercultura, muitos foram os gêneros discursivos que migraram do formato material para o digital e ganharam novos contornos, novas funcionalidades, acelerando, assim, tanto a velocidade de interações quanto dirimindo distâncias espaciais e dificuldades de acesso. Consequentemente, os discursos e seus significados trafegam mais rapidamente, estão mais acessíveis e têm maior mobilidade inter, intra e 


\section{REVISTA DA ABRALIN}

transcultural na promoção de relações dialógicas marcadas por uma série de antônimos: consenso/dissenso, inclusão/exclusão, tolerância/intolerância, paz/guerra, amor/ódio.

Contudo, essas recontextualizações ao formato digital não se restringem aos gêneros discursivos; elas englobam também uma vasta gama de recursos potencializadores do ato comunicativo. Entre os recursos verbo-imagéticos transeuntes do meio digital merecem destaque os memes de internet, que servem aos sujeitos de culturas diversas enquanto transmissores de suas crenças, atitudes, ideologias e valores socioculturalmente engendrados.

Contribuições assertivas para essas discussões são profusas na ADC (FAIRCLOUGH, 2001; 2003; RESENDE; RAMALHO, 2019; VIEIRA; RESENDE, 2016) que propõe uma análise discursiva comprometida não apenas com as questões linguísticas em uma vasta gama de textos, mas também, e por meio delas, provocar fricções nas estruturas sociais com vistas à transformação da sociedade. Aprofundaremos os debates sobre a ADC na próxima seção, trazendo à tona alguns de seus conceitos-chaves, bem como as categorias analíticas que julgamos oportunas a nossas investigações.

\section{Análise de Discurso Crítica (ADC)}

As pesquisas em ADC têm se intensificado e apresentado ainda mais desafios a pesquisadoras/es debruçadas/os sobre os estudos da linguagem e engajadas/os na compreensão de agendas sociais urgentes imbricadas nas práticas discursivas que envolvem grupos historicamente oprimidos. Questões como homofobia, misoginia, racismo, xenofobia etc. ganham ainda mais proeminência nos dias atuais ao serem legitimadas por discursos de grupos hegemônicos que se utilizam da linguagem para naturalizarem relações de opressão e exclusão sistematizadas em diversos gêneros discursivos que permeiam e dão suporte às relações sociais, especialmente, por meio das tecnologias digitais e mídias de massa (PEREIRA et al., 2020).

Desse modo, destacamos a proeminência do caráter qualitativo (não se limitando a ele, obviamente) que a ADC oferece, apontando caminhos para além de descrições objetivas, um estímulo a investigações críticas, sistemáticas e coerentes dos dados estudados, que possibilita verificar a conexão entre aspectos da prática sociocultural em pauta. Orientados por essas reflexões, entendemos que analisar criticamente o discurso na atualidade implica em

\footnotetext{
[...] compreender o termo "discurso" a partir da polissemia que lhe é constitutiva, a saber, discurso como: (i) enunciado oral, escrito ou multimodal, (ii) mensagem solene e extensa, (iii) conjunto de enunciados característicos do modo de pensar e/ou agir de dados grupos e, por fim, (iv) como uma dimensão da prática social (destaque para essa última acepção, que ocupa uma história nos estudos da linguagem) (PEREIRA et al., 2020, p. 21).
}

O conceito de discurso é um marco basilar nos estudos discursivos de natureza crítica, não sendo, entretanto, um uníssono entre pesquisadoras/es da área. Não obstante as convergências e divergências, podemos afirmar, de maneira inequívoca, que as contribuições de Michael Foucault para a concepção desse termo são bastante prolíficas. Foucault concebe o discurso como um composto de 


\section{REVISTA DA ABRALIN}

princípios anônimos, históricos, sempre determinados "no tempo-espaço, que definiram, em uma dada época, e para uma área social, econômica, geográfica ou linguística, as condições de exercício da função comunicativa" (FOUCAULT, 2008[1969] apud PEREIRA; TEIXEIRA; PEREIRA, 2020, p. 25).

Outro aspecto essencial à ADC é apresentado por Resende e Ramalho (2019), que destacam a natureza complexa, trans e multidisciplinar da ADC, que abarca uma amplitude de abordagens teórico-metodológicas e consubstancia estudos em áreas como as ciências da linguagem e as ciências sociais. Destarte, a ADC não pode ser considerada como uma abordagem única e estável, mas sim, como um construto aberto, instável e heterogêneo de teorias e métodos empenhados em investigar o discurso em práticas contextualizadas ${ }^{4}$ (VIEIRA; RESENDE, 2016).

Por conseguinte, a ADC estabelece uma relação dialógica bastante frutífera com a LSF de Michael Halliday - já mencionada na seção anterior - que corrobora a importância de considerarmos as escolhas das/os falantes/escritoras/es, já que elas operam em todos os níveis do discurso (lexical, sintático, modal), com a finalidade de se depreender o grau de expressividade inerente a uma dada situação comunicativa. Nessa ótica, há que se considerar os aspectos de hibridização de gêneros, estilos, discursos no intuito de lançar luz sobre os elementos inerentes à linguagem e ao contexto social para que se possa depreender seus significados com maior acurácia.

Uma visão mais holística do contexto em foco demanda a convergência dialógica entre a ADC e a LSF como eloquente recurso ao aproximar o texto e o contexto, o linguístico e o social. Esse alinhamento teórico possibilita que perscrutemos a linguagem "[...] por vários prismas, seus diferentes modos de enxergar e sentir a sociedade e o mundo, a fim de melhor compreender os mecanismos sociais de dominação e resistência, ou de emancipação e transformação social" (BARROS, 2018, p. 46). Dada a complexidade das relações humanas, podemos inferir que são vários os conceitos emergentes dessas duas abordagens. Entre esses conceitos, enfatizamos, além do discurso, os conceitos de poder, ideologia e hegemonia.

Nascimento et al. (2020) afirmam que para a ADC, há uma correlação entre linguagem e poder, que é concebido em sua dimensão política e está, dessa forma, relacionado à estrutura social. As/os pesquisadoras /es amparam-se em Fairclough (1989) para apontar dois aspectos dessa relação: o poder no discurso e o poder por trás do discurso. O primeiro aspecto acontece em interações cara a cara em que indivíduos impõem restrições de conteúdos, de relações, de papéis que sujeitos ocupam em situações de interação sociodiscursiva, como, por exemplo, a relação pastor/a e fiel em um culto. Nesse contexto específico, apenas um/a das/os interactantes possui discurso autorizado e legitimado pela posição sociocultural de liderança que ocupa.

Contudo, esses aspectos são instáveis, visto que há sempre uma disputa pelo poder, ora por parte dos indivíduos que o detêm, ora pelas/os desprovidas/os dele. Nesse embate, a ideologia desempenha papel fundamental seja para mantê-lo, seja para conquistá-lo. Isso implica no fato de que

\footnotetext{
${ }^{4}$ Nesse sentido, "não apenas os avanços trazidos pela abordagem de Norman Fairclough são identificados com a ADC, mas também as perspectivas de autores como Teun Van Dijk (1989), Ruth Wodak (1996), Blommaert (2005), Theo van Leeuwen (2008), entre outros/as. Todas essas abordagens são legitimamente associadas à Análise de Discurso Crítica, e cada uma delas provê acercamento teórico e instrumental específico para pesquisas discursivas" (VIEIRA; RESENDE, 2016, p. 20).
} 


\section{REVISTA DA ABRALIN}

a $\mathrm{ADC}$ está atenta às ideologias sustentadas e disseminadas por meio de relações assimétricas de poder. O discurso e a língua, consoante Fairclough, são elementos ideológicos nas lutas pelo poder, não sendo este vitalício, uma vez que as hegemonias inerentes às relações de poder são instáveis, portanto, sujeitas a rupturas (NASCIMENTO et al., 2020).

Consoante essas/es autoras/es, a ADC concebe o poder como imanente às estruturas sociais que, por sua vez, não se constituem de apenas um indivíduo, mas das relações estabelecidas entre conjuntos de indivíduos. Assim, o conceito de poder está intimamente atrelado ao conceito de hegemonia que chama atenção para os efeitos ideológicos dos textos no favorecimento de grupos específicos, subjugando outros indivíduos na luta pela preservação da conjuntura em que se encontram.

Nessa seara de estudos, a ideologia é outro conceito caro e que tem função primordial de estabelecer e sustentar relações de poder. Todavia, não é apenas com as propriedades linguísticas de dada elocução que ela se relaciona, já que está mais ligada com os indivíduos engajados no ato comunicativo e com suas intenções. Assim sendo, precisamos conceber a análise textual a partir das vozes que são representadas de maneira direta e indireta, passiva e ativa, nominal e impessoal, e estar sempre atentas/os aos desdobramentos e às reflexões dessas escolhas perante a/o interlocutor/a. Fairclough $(1992 ;$ 2001) defende a existência material da ideologia, sua capacidade de constituição dos sujeitos e sua atuação por meio dos posicionamentos sociais das pessoas. Tanto a constituição quanto os posicionamentos acontecem no interior de instituições sociais, como a educação, a religião, a família, a mídia, o direito (VIEIRA; MACEDO, 2018).

Na concepção crítica proposta por Thompson (2002a), a ADC concebe a ideologia enquanto ente carregado de negatividade, atuando como instrumento semiótico de lutas de poder. Dito de outra maneira, a ideologia atua na manutenção, ainda que temporária, da hegemonia por meio da propagação de representações particulares do mundo, colocando-se enquanto única possibilidade válida e legítima, atuando em favor de forças opressoras. Ante o exposto, propomos que o desvelamento das ideologias seja visto como recurso para a superação das relações assimétricas de poder, tendo como resultado, a emancipação de indivíduos em estado de opressão e exclusão (VIEIRA; RESENDE, 2016).

Fairclough advoga, assim, que o desvelamento das ideologias necessita de reflexões que estabeleçam relações diretas entre os textos e a sociedade; e que é preciso considerar o corpus de textos analisados sem perder de vista seus efeitos sobre as relações de poder. Por conseguinte, o aspecto nevrálgico "da relação entre ideologia e textos é que, como elementos de eventos sociais, os textos têm efeitos causais, ou seja, mudam pessoas (crenças, atitudes, valores), mudam relações sociais e mudam o mundo material" (VIEIRA; MACEDO, 2018, p. 60), e isso atesta a relação dialética entre o discurso e a sociedade.

Embasado no conceito de Gramsci (1988; 1995), Fairclough (1997; 2001a) concebe a hegemonia, outro elemento caro à $\mathrm{ADC}$, enquanto dominação exercida por um determinado grupo detentor do poder sobre outro, arraigada mais no consenso que no emprego da força. Contudo, essa hegemonia não é estável, havendo, assim, a luta hegemônica focada nos pontos de instabilidade nas relações hegemônicas. Gramsci afirma que "o poder de uma das classes em aliança com outras forças sociais sobre a sociedade como um todo nunca é atingido senão parcial e temporariamente" (RESENDE; RAMALHO, 


\title{
REVISTA DA ABRALIN
}

2019, p. 43). Assim, para que determinados grupos conservem sua hegemonia, urge que se estabeleça e sustente liderança nos campos moral, político e intelectual na vida em sociedade. Ademais,

\begin{abstract}
há distintas formas de se instaurar e manter a hegemonia, dentre elas, a luta hegemônica travada no/pelo discurso. Quando essas perspectivas favorecem algumas poucas pessoas em detrimento de outras, temos representações ideológicas, voltadas para a distribuição desigual de poder baseada no consenso (VIEIRA; RESENDE, 2016, p. 26).
\end{abstract}

Por este ângulo, é importante que estejamos sempre atentas/os ao potencial dos discursos materializados no todo multimodal dos memes de internet, em razão de eles serem frequentemente empregados por forças hegemônicas como poderosos artifícios para a instauração, sustentação e universalização de discursos particulares mobilizados por ideologias excludentes, profundamente arraigadas em concepções eurocêntricas do mundo, marcadas pelo negacionismo e uma miríade de preconceitos que oprimem, exploram, subvalorizam, silenciam e matam indivíduos marginalizados e em situação de vulnerabilidade social.

A ADC, embasada na LSF, recontextualiza as macrofunções da linguagem ${ }^{5}$ propostas por Halliday consoante a visão de Fairclough. Tal recontextualização propõe, ao invés de três macrofunções, três significados principais, a saber: o acional (concepção do texto como forma de ação), o representacional (modos particulares de representar aspectos do mundo) e o identificacional (modo de ser, identidades construídas por meio do discurso) (RESENDE; RAMALHO, 2019).

Cada um desses significados está diretamente atrelado aos demais, assim, "representações (discursos) particulares podem ser legitimadas em maneiras particulares de ação (gêneros [entre outros recursos]) e impostas em maneiras particulares de identificação (estilos), por exemplo" (RAMALHO, 2005, p. 293). Assim, discursos imbuídos de valores, crenças, atitudes e posicionamentos ideológicos podem ser legitimados por meio dos memes de internet, resultando na naturalização e legitimação de concepções particulares de um coletivo de indivíduos sobre si mesmos e sobre os outros.

Vieira e Resende (2016, p. 114) alertam para o fato de que "os três momentos da ordem do discurso (discursos, gêneros, estilos) são realizados em traços semânticos, gramaticais e lexicais de textos", ou seja, maneiras relativamente estáveis de representação, (inter)ação e identificação nas práticas sociais são materializadas em textos. Logo, para dar conta da complexidade analítica inerente à $\mathrm{ADC}$, é necessário o suporte de categorias analíticas que estejam balizadas pelos objetos estudados e pelos objetivos propostos pelas/os pesquisadoras/es do discurso. Destarte, entendemos por categorias analíticas

[...] formas e significados textuais associados a maneiras particulares de representar, de (inter)agir e de identificar(-se) em práticas sociais situadas. Por meio delas, podemos analisar textos buscando

\footnotetext{
${ }^{5}$ Recuperando reflexões abordadas nas seções anteriores, são três as macrofunções que atuam simultaneamente nos textos: a ideacional, a interpessoal e a textual.
} 


\section{REVISTA DA ABRALIN}

mapear conexões entre o discursivo e não discursivo, tendo em vista seus efeitos sociais (VIEIRA; RESENDE, 2016, 114) ${ }^{6}$.

Tendo em mente os objetivos aqui propostos, recorremos ao significado representacional que, conforme Fairclough (2003), demanda a consideração de três elementos fundamentais para avaliação das composições. Primeiro, considerar os processos realizados por meio dos verbos. Segundo, atentar aos participantes que podem ser identificados pelos sujeitos ou objetos (diretos/indiretos) dos verbos. E por último, estar atento aos adjuntos adverbiais, que indicam as circunstâncias espaciais e/ou temporais a fim de identificar aspectos como inclusão/exclusão bem como suas implicações particulares nesse processo específico de representação.

Além disso, há que se considerar outra categoria seminal de análise discursiva: a representação dos atores sociais. Amparadas em van Leeuwen (1997; 2008), Vieira e Resende (2016) asseveram que essa categoria está relacionada às representações de práticas sociais particulares, isso implica dizer que pontos de vista subjetivos determinam essas representações e, destarte, revelam os atores que estão envolvidos em diferentes práticas (discursivas) e de diferentes modos.

Como exemplos, as autoras elencam técnicas de manipulações linguísticas como: a exclusão de atores dos textos; ou a inclusão cujo agenciamento é ofuscado ou enfatizado; representações referenciadas pelas atividades ou pelos enunciados proferidos por esses atores; ou ainda, serem representados balizados por julgamentos acerca do que são ou fazem, entre outra possibilidades. As autoras afirmam que "os modos pelos quais os atores podem ser representados em textos não estão rigorosamente relacionados a formas linguísticas, mas sim a escolhas socio-semânticas, daí o conceito de 'ator social"' (VIEIRA; RESENDE, 2016, p. 151). Tendo em consideração a natureza subjetiva dessas representações, é possível haver implicações ideológicas nas maneiras como se escolhem representar os atores sociais.

Na próxima seção, discutiremos os memes de internet em seu aspecto verbo-imagético, artefatos culturais potencializadores da construção de sentido e repositórios de posicionamentos ideológicos a serviço de forças hegemônicas.

\section{Memes de internet}

Os memes de internet (CHAGAS, 2020) têm sido alvo de intensas inquietações e pesquisas empenhadas em apreender seus atributos, elementos constitutivos e propósitos. Não obstante os consensos e dissensos acerca de sua definição, consideraremos os memes, essencialmente, em seu aspecto verbo-imagético, enquanto recursos catalizadores da construção de significados nas interações virtuais.

\footnotetext{
${ }^{6}$ As autoras (VIEIRA; RESENDE, 2016) apresentam, baseadas em Fairclough (2003a), aspectos discursivos textuais que podem nortear a seleção de categorias adequadas para um estudo particular; entre elas destacamos: estrutura genérica, intertextualidade, presunção, interdiscursividade, representação de eventos/atores sociais, identificação e modalidade.
} 


\section{REVISTA DA ABRALIN}

Segundo Lima-Neto (2020), pode-se tomar os memes em duas concepções: clássica e online. Na concepção clássica, os memes são considerados padrões culturais passados de mente em mente que contribuem para a (re)construção das mentalidades de grupos sociais específicos. Nessa lógica, são exemplos de memes: músicas, comportamentos, roupas, modos particulares de agir, estilos arquitetônicos etc. Em contrapartida, temos o meme de internet (online) que se refere ao consumo e à célere disseminação de uma ideia particular materializada em textos multissemióticos ou outros artefatos culturais (KNOBEL; LANKSHEAR, 2007 apud LIMA-NETO, 2020).

Concentramos nossas reflexões nos memes de internet (online), motivados por uma série de razões como notícias/eventos de impacto macrossocial, produzidos, consumidos e propagados na rede por meio de sites, páginas e canais especializados, redes sociais, e-mails e até mesmo na mídia impressa e nos textos acadêmicos em que pesquisadoras/es têm direcionado esforços para compreender esse fenômeno sociocultural e a intricada gama de significados possíveis em sua orquestração/desenho e reprodução (que também passa por redesenhos e mixagens), distribuição e consumo. Nesses processos de produção de sentido, há uma ebulição de possibilidades sígnicas por meio da evolução e da manipulação de mídias que consubstanciam as linguagens, pois como afirma Santaella (2007, p. 81),

\footnotetext{
Além de crescerem na medida exata em que cada novo veículo ou meio é inventado, as linguagens também crescem através do casamento entre meios. [...] Enfim, o universo midiático nos fornece uma fartura de exemplos de hibridização de meios, códigos e sistemas sígnicos. São esses processos de hibridização que atuam como propulsores para o crescimento das linguagens. Não é à toa que as ecologias midiáticas, povoadas de linguagens dos mais diversos tipos, já tomaram literalmente conta do mundo.
}

Consequentemente, a evolução desses memes se dá de diversas formas: por meio de comentários, imitações, paródias, entre outras, e se espalham rapidamente, ou "viralizam", ganham e perdem popularidade com marcante efemeridade. Sua proliferação é voluntária em comunidades/redes sociais e não atendem a rotas predeterminadas, geralmente, desafiando esforços de controlá-los. Esse fenômeno tem ganhado tanta visibilidade que despertou a curiosidade de um número cada vez mais crescente de interessadas/os, o que resultou na construção de sites totalmente comprometidos com a curadoria, o estudo e a hospedagem destes textos com maior proeminência no cenário atual ${ }^{7}$. Até mesmo profissionais de relações públicas e de marketing têm recorrido aos memes de internet como molas propulsoras de sucesso (BAUCKHAGE, 2011).

Toda a popularidade dos memes online resulta em uma intricada e desafiadora gama de temáticas, especialmente de cunho social, cultural e político, cuja propagação na internet resulta em ainda mais visibilidade para pautas bastante pertinentes na sociedade atual, concentrando-se em nichos de conhecimento como o feminismo, as relações de classe social, o eurocentrismo, o racismo.

\footnotetext{
${ }^{7}$ Apesar de a fonte consultada apresentar alguns endereços eletrônicos de sites sobre memes, trazemos também nossas sugestões: www.knowyourmeme.com, www.memebase.com, www.imgur.com, www.museudememes.com, https://pt.memedroid.com/.
} 


\section{REVISTA DA ABRALIN}

No tocante ao racismo, foco de nossos estudos aqui, trazemos à tona os memes "Nego", que ganharam os espaços discursivos digitais nos últimos anos e têm propalado significados à primeira vista (para muitas pessoas) jocosos e risíveis, mas que, após uma reflexão mais profunda, podem surpreender (ou até mesmo assustar) aquelas/es com pensamento crítico-reflexivo proficiente o bastante para depreender as reais intenções, os posicionamentos, as crenças, os silenciamentos e os (pre)conceitos intricados no todo multimodal desses artefatos culturais verbo-imagéticos.

De acordo com Souza Jr. (2016), os memes Nego são provenientes de espaços digitais particulares, como a multiplataforma digital Whatsapp, alcançando espaços digitais públicos de grande abrangência como o Facebook e o Twitter. Seu composto multimodal caracteriza-se pela representação imagética (ou inferida) de um indivíduo (ou mais) negro sendo associado a situações, eventos, circunstâncias que se pretendem associadas à desvalorização do indivíduo. Em vista disso, faz-se urgente considerarmos criticamente os aspectos sócio-históricos, culturais, econômicos e políticos subjacentes às representações em curso para que, dessa forma, possamos deslindar o que subjaz à complexa tessitura semiótica dos memes.

Com foco nesse fato, surgem-nos indagações inquietantes como: Esses memes são mesmo apenas brincadeiras? É exagero atribuir racismo a seu teor "descomprometido"? É sensato e socialmente ético desconsiderar as possíveis ideologias (des)veladas em seu todo multissemiótico? É possível, balizado pelo pensamento crítico-reflexivo, transformar as relações e as práticas sociais rumo à construção de uma sociedade menos injusta e mais equitativa? Concentraremos nossas reflexões na busca de respostas a essas perguntas a partir dos procedimentos metodológicos que balizarão nossas análises na próxima seção.

\section{Procedimentos metodológicos}

O corpus constitui-se de quatro memes pertinentes ao coletivo memes Nego que foram coletados de sites diversos na internet (todas as fontes indicadas na legenda de cada imagem) entre os dias 01 de janeiro de 2021 e 20 de abril do mesmo ano. Esse recorte temporal é pertinente devido a eventos que têm dado ainda mais saliência às pautas dos movimentos negros não apenas no Brasil, mas em várias nações. Entre esses eventos, destacamos os posicionamentos individuais questionáveis de participantes do reality show Big Brother Brasil, edição 2021, a eleição da primeira mulher negra para o cargo de vice-presidenta dos Estados Unidos, os novos levantes contra violência policial nos Estados Unidos contra pessoas negras, entre outros.

Para a análise de natureza descritivo-qualitativa do corpus coletado, recorremos às bases teóricas de cunho semiótico social (HODGE; KRESS, 1988; JEWITT, 2014) e da LSF (HALLIDAY, 1978) por considerar que os estudos da linguagem demandam uma perspectiva que considere não apenas os aspectos linguísticos dos textos, mas também os elementos multimodais que os constituem bem como o contexto sócio-histórico, cultural e as intenções subjacentes ao ato comunicativo. 


\section{REVISTA DA ABRALIN}

A ADC (FAIRCLOUGH, 2001; 2003; RESENDE; RAMALHO, 2019; VIEIRA; RESENDE, 2016) substancia nossa discussão por meio da categoria analítica do significado representacional, que embasará nossas investigações acerca das "realidades"8 representadas nos textos em foco. Apoiamo-nos, também, na categoria de representação dos atores sociais no tocante a desvelar os significados subjacentes aos discursos materializados nos memes Nego, oferecendo recurso fértil para a apreensão dos modos como os indivíduos representam o mundo e a si mesmos.

Para esse fim, consideramos a modalidade seletiva dessas representações para identificar como esses atoes sociais foram idealizados nos textos, ou seja, por meio de inclusão/exclusão, pronome/nome, função gramatical, atividade/passividade, pessoalidade/impessoalidade, nominado/classificado, genérico/específico ${ }^{9}$.

\section{Análise de corpus}

Analisaremos os memes a seguir no tocante aos desvelamentos de posicionamentos de ideologia marcadamente racista. Ademais, refletiremos sobre os aspectos cômicos atribuídos aos memes Nego, problematizando o que subjaz aos discursos materializados em seu todo textual.

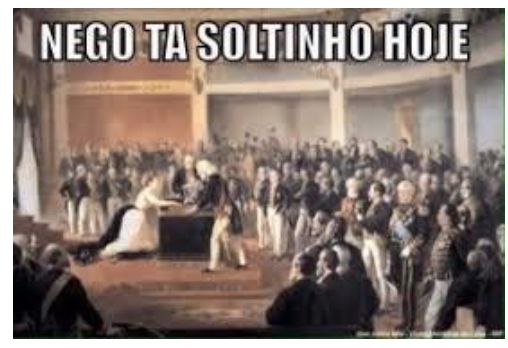

FIGURA 1

Fonte: https://images.app.goo.gl/XdKTU46JrhKbayhaA

Nesse meme, a análise linguística aponta que o verbo de ligação "ser" (Nego ta soltinho hoje) indica um estado transitório do ator social representado pelo sujeito da oração (Nego); isso pode sugerir que o predicativo do sujeito (soltinho) seja um concessão feita por tempo limitado, pois, dada a visão essencialista que muitas pessoas propagam de pessoas negras, elas não poderiam ser (verbo de ligação que indica permanência) livres, mas sim, estarem livres (soltinhas) por um determinado período, que é indicado pelo advérbio de tempo "hoje". O teor irônico do predicativo do sujeito

\footnotetext{
${ }^{8}$ A função das aspas na palavra "realidade" opera no sentido de relativizar a representação do mundo real, relacionando tal representação a perspectivas particulares de concepção dessa "realidade", atendendo, dessa forma, a discursos particulares (RESENDE; RAMALHO, 2019, p. 89).

${ }^{9}$ Esses processos de escolhas de representação dos atores sociais foram sugeridos por Fairclough (2003, p. 145-146). Todavia, segundo o autor, essas escolhas não se esgotam, podendo, pois, efetuar-se de outras maneiras.
} 


\section{REVISTA DA ABRALIN}

"soltinho" também merece relevância, porque sugere uma confirmação do caráter ilusório da realidade sugerida (estar livre), isto é, as pessoas negras pensam que estão livres, no entanto, a ideologia racista que opera nesse meme sustenta que essa liberdade é ilusória.

A intertextualidade é requerida para a construção global do sentido, no meme, por meio do quadro Juramento da Princesa Isabel, do pintor Victor Meirelles (1875), que é utilizado em uma referência à libertação de indivíduos escravizados no Brasil, assim, a obra atua como plano de fundo para materializar o poder de decisão da branquitude ${ }^{10}$ de decidir os rumos possíveis às vidas de pessoas negras. O meme em pauta apresenta uma relação vetorial em que a imagem parte do centro para as laterais, sendo que, no centro, encontra-se um homem branco, de pé diante da representação de uma mulher, membro da realeza, a princesa Isabel, que é representada em posição de submissão aos deveres a ela impostos pela conjuntura sócio-política de então. Essa representação desvela um traço profundamente marcante da sociedade da época e que prevalece atuante até a atualidade: o patriarcado, consolidado em uma relação assimétrica de poder.

No tocante à representação dos atores sociais, enquanto as pessoas negras são verbalmente representadas de maneira genérica por meio do sujeito da oração (Nego, expressão popular referente ao substantivo masculino singular "negro"), a imagem representa apenas pessoas brancas, majoritariamente homens. É relevante atentar para a exclusão das pessoas negras na imagem, bem como a pouca representatividade de referentes femininos e a flagrante ausência de referentes diretos às mulheres negras, visto que esses aspectos reforçam o privilégio de decisão da branquitude patriarcal, sugerido como natural à existência de homens brancos da elite brasileira, o que lhes confere e assegura prerrogativas exclusivas.

Nesse contexto, o que subjaz ao teor pretensamente "cômico" desse meme oferece um panorama das mazelas enfrentadas pelos sujeitos escravizados no Brasil não apenas durante o período da escravidão, mas também para além da abolição e com desdobramentos na sociedade atual, profundamente excludente. Uma análise atenta desse meme provoca reflexões que podem conscientizarnos de que os esforços pela transformação da sociedade precisam se intensificar, além de lembrarnos que os direitos já conquistados pelas lutas dos movimentos negros no Brasil e no exterior, embora exitosos em vários níveis, ainda são insuficientes para reparar dívidas históricas e promover uma efetiva mudança nas estruturas sociais.

Constatamos, dessa forma, que é possível descrever o discurso presente no meme da figura 1 , como predominantemente racista, pois, além da representação imagética do ator social negro ser excluído de sua composição, sendo referido apenas de maneira verbalmente jocosa, a única mulher em evidência é a princesa Isabel - branca e europeia, que aparece em posição de subordinação aos homens brancos representados. A menção à escravidão ratifica o complexo jogo de construção de

\footnotetext{
10 "[...] a branquitude refere-se à identidade racial branca, a branquitude se constrói. A branquitude é um lugar de privilégios simbólicos, subjetivos, objetivo, isto é, materiais palpáveis que colaboram para construção social e reprodução do preconceito racial, discriminação racial 'injusta' e racismo" (SILVA, 2011). Disponível em: https://www.geledes.org.br/definicoes-sobre-branquitude/. Acesso em: 15 maio, 2021.
} 


\section{REVISTA DA ABRALIN}

sentido com vistas à naturalização de uma situação de conquistas sutis de direito que não modificam efetivamente a estrutura da questão do direito à liberdade.

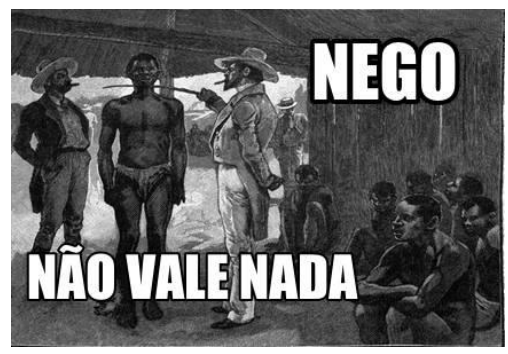

FIGURA 2

Fonte: ttps://images.app.goo.gl/n2VqtQvVdFXjMDSF9

No meme "Nego não vale nada", há a representação em preto e branco de dois homens brancos, vestindo trajes de época, reportando-se com altivez a um homem negro, vestido em um pedaço de pano que lhe cobre as partes íntimas; inerte, ele está de pé para que os homens brancos o avaliem. Entrementes, outros homens negros, em trajes semelhantes, sentados no chão, representados na base da imagem, aguardam sua vez de serem, também, avaliados e, posteriormente, negociados/vendidos.

A estrutura morfossintática nesse meme traz o verbo transitivo direto "valer", que faz uma avaliação quantitativa da pessoa negra, do corpo negro, não expressa em valores numéricos, mas sim, por meio do pronome indefinido "nada", que exerce, por sua vez, a função de objeto direto. Assim, pode-se deduzir que, tomada como produto comercializado, a pessoa negra escravizada é totalmente desprovida de valor (simbólico). Um aspecto inerente ao texto verbal desse coletivo de memes (Nego) é o fato de o ator social ser sempre representado na posição de sujeito em uma declaração afirmativa ou negativa sugerindo elementos tomados como "naturais" à existência de pessoas negras.

Enfatizamos, agora, a voz ativa do verbo na forma negativa "não vale"; esse traço linguístico, embora possa conferir o agenciamento de um sujeito, vem na contramão desse agenciamento e representa o sujeito negro como afetado por uma determinada percepção da "realidade" representada. Nessa percepção, o agenciamento é conferido pela representação imagética dos homens brancos representados em uma relação assimétrica de poder, que relega o indivíduo negro à posição de inferioridade e limita sua existência a um bem material. No todo verbo-imagético desse meme, os homens brancos estão em maior saliência, um deles ocupa o centro do texto, em alinhamento vertical, e compartilha do agenciamento da venda das pessoas negras, referenciadas verbalmente de maneira genérica pelo termo "nego" e, visualmente pelas imagens de homens desprovidos de poder, impossibilitados de ação ativa no reconhecimento de seu valor.

A representação dos atores sociais nesse meme tenciona legitimar o discurso de grupos hegemônicos que reforçam a desvalorização de pessoas negras e intenta naturalizar percepções colonizadoras desafeitas à multiculturalidade, aos costumes, às crenças e às epistemologias de bases nãoeuropeias, corroborando essa visão por meio da declaração negativa "Nego não vale nada". Assim, 


\section{REVISTA DA ABRALIN}

tem-se a legitimação de práticas desumanizadoras da sociedade como o tráfico e a comercialização de seres humanos negros representada por meio de recursos multissemióticos pretensamente cômicos. Outro aspecto problematizador inerente a esse meme refere-se à negligência às dores múltiplas causadas às pessoas escravizadas e comercializadas ao serem arrastadas de seu local de origem, separadas de suas famílias, exploradas e violentadas para satisfação de seus opressores.

A partir dessas reflexões, depreendemos que há uma incapacidade (ou desinteresse) subjacente ao discurso racista, que aventa ideologias de indivíduos resistentes em colocar-se no lugar do/a outro/a, mostrando-lhes, assim, empatia e solidariedade. Esse fato ganha ainda muita repercussão na sociedade atual em que, indo de encontro ao que preconiza a Organização das Nações Unidas (ONU), no Protocolo de Palermo (2003), o tráfico de pessoas segue atuante e destaca-se como terceiro negócio ilícito mais rentável do mundo, ficando atrás apenas do tráfico de drogas e de armas em que as/os desvalidas/os do capital, em relações de intensa opressão, são as maiores vítimas.

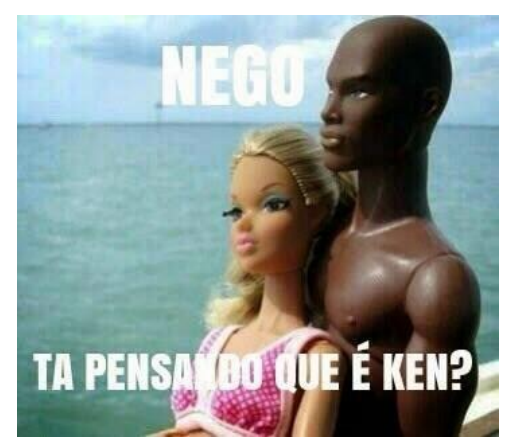

FIGURA 3

Fonte: http://caveiranerd.blogspot.com/2015/03/memes-nego.html

A representação verbo-imagética traz uma boneca ocupando o centro da imagem, e um boneco, representado na lateral, servindo de apoio a ela que, de pé e de costas, apoia-se sobre seu torso. Na parte superior, um texto verbal que diz "Nego", e na parte inferior, o complemento que diz "ta pensando que é ken?". Nesse todo multissemiótico, a saliência das representações produz um jogo de cores que contrastam o tom claro do texto verbal, da paisagem (oceano e céu aberto), unido à claridade de todos os elementos constituintes da boneca, com o tom escuro da pele do boneco, representação de um homem negro sem camisa e de cabeça raspada. Ambos os bonecos representam pessoas jovens, com fenótipos semelhantes: ela é representada como magra, e ele, como forte, musculoso. Os bonecos são da famosa linha Barbie, que tem influenciado gerações e despertado controvérsias acerca das representações sociais.

A estrutura morfossintática que intitula esse meme: "Nego tá pensando que é ken?", traz um jogo fonológico entre o substantivo próprio Ken, de origem anglófona, e o pronome interrogativo "quem" da língua portuguesa, tratando esses termos como homófonos. O texto verbal emprega o gerúndio do verbo "pensar" (ta pensando - forma coloquial de "está pensando"), indicativo de uma ação que está em andamento no momento da elocução, na forma interrogativa, em tom satírico indagativo, uma censura à representação de um homem negro em uma posição social que, supostamente, ele não poderia 


\title{
REVISTA DA ABRALIN
}

ocupar, ou seja, a posição de Ken, boneco de pele branca, criado para atuar como namorado da boneca Barbie, também branca, portanto, não podendo ser representado por um homem negro.

A análise textual nos permite também refletir sobre a classificação genérica do ator social representado pelo termo "Nego" (recorrente em quase todos os memes desse coletivo); isso sugere que todos os indivíduos negros compartilhem das mesmas características, ignorando atributos de singularidade cultural e social. A seleção verbo-imagética desse texto reforça o caráter de inadequação desse ator social (homem negro), ocupante de um espaço originalmente criado para um ator social de pele branca e membro de uma estrutura social que lhe confere privilégios. Nessa linha de raciocínio, ao mesmo tempo em que o ator social (nego) está explícito no texto, tanto verbal quanto imagético, ele é simbolicamente suprimido de um espaço ao qual não deveria ter acesso.

Essas reflexões suscitam temáticas como a consciência de classe que está diretamente atrelada ao problema racial em que o racismo é, historicamente, elemento divisor tanto entre as classes quanto dentro delas. Para aprofundar a discussão, Almeida (2020, p. 187) afirma que

\begin{abstract}
nos momentos de crise, em que há aumento do desemprego e rebaixamento dos salários, o racismo desempenha um papel diversionista bastante importante, pois os trabalhadores atingidos pelo desemprego irão direcionar sua fúria contra as minorias raciais e sexuais, que serão responsabilizadas pela decadência econômica por aceitarem receber salários mais baixos, quando não pela "degradação moral" a que muitos identificarão como motivo da crise. O racismo será, portanto, a forma dos trabalhadores brancos racionalizarem a crise que lhes trouxe perdas materiais e de lidarem com as perdas simbólicas.
\end{abstract}

Isso nos leva a refletir, com base na representação dos atores sociais no meme em questão, acerca da má distribuição de riquezas que dita o espaço relegado às pessoas negras na pirâmide social e legitima sua subjugação ao capital e a alienação de sua força de trabalho. Os significados subjacentes a esse meme desvelam posicionamentos defensores de que as/os negras/os não podem ter mobilidade social, acesso a renda, poder aquisitivo, alto padrão de vida e nível de escolaridade, declarando serem esses privilégios da branquitude ao mesmo tempo em que naturalizam os espaços reservados às pessoas negras enquanto trabalhadoras braçais, a quem caberia o exercício de funções menos privilegiadas, mal remuneradas, menos estáveis e seguras.

Esses pensamentos são corroborados por eventos do dia a dia dos grandes centros urbanos em que edifícios reservam elevadores especiais para seus residentes, e elevadores de serviço às pessoas com trabalhos menos privilegiados. Aliás, são recorrentes os discursos que aventam quem são as pessoas que têm permissão para viajar de avião ou ir à Disney e quem são as pessoas que precisam "aprender qual é seu lugar" para, assim, evitar "incômodos"11. Sob essa ótica, percebemos a urgência de se promover mudanças na sociedade a partir da consciência de classe por meio da compreensão das relações contraditórias de produção e o acesso aos bens produzidos. Para tanto, há que se promover uma revolução nas relações de trabalho por meio da mobilização das forças populares, instigando-as ao desenvolvimento de ações efetivas de enfrentamento coletivo dos conflitos, para, assim,

\footnotetext{
${ }^{11}$ Leia mais a respeito em https://www.cartacapital.com.br/opiniao/ultimamente-tem-um-monte-de-pobre-no-avia\%CC\%83o$\underline{\text { sinto-o-cheiro-de-longe/. }}$
} 


\section{REVISTA DA ABRALIN}

causar tensões nas estruturas sociais, combater discursos afeitos à concentração de riquezas, à segregação espacial e ao preconceito de classe e de raça.

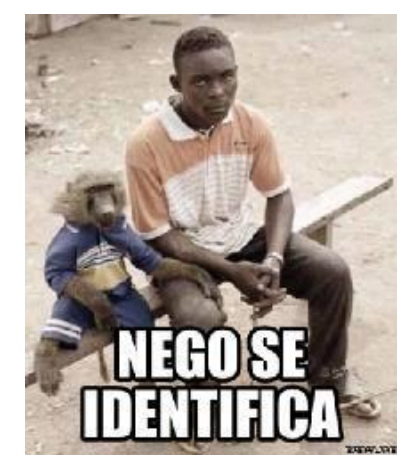

FIGURA 4

Fonte: https://images.app.goo.gl/A7XKd1EAxYpXpKz79

Nesse meme, marcado por cores esmaecidas e contrastes entre tons claros e escuros, temos a representação de um homem negro que usa roupas simples (camiseta, calça e chinelos de dedo), sentado em um banco de madeira (que faz um corte diagonal na imagem) a céu aberto, tendo a seu lado um babuíno ${ }^{12}$, que também usa roupas simples (camiseta e shorts), colocando a mão esquerda sobre a perna direita do homem a sugerir proximidade entre os dois. O homem tem maior proeminência na imagem, em primeiro plano; o babuíno, com menor saliência, é projetado à sua direita, quase na base da imagem, onde se encontra o texto verbal na cor branca "Nego se identifica".

Com foco no texto verbal, o ator social, Nego, aparece no início da estrutura textual, identificando o sujeito da oração que está diretamente ligado ao verbo "identificar", que, por sua vez, é empregado em sua conjugação pronominal por meio de próclise (se identifica); esse recurso estabelece uma relação de comparação entre as duas principais referências imagéticas do meme: o homem negro e o babuíno. Aqui, pode-se perceber traços discursivos da animalização da pessoa negra ao compará-la a um não-humano, a um primata, esse discurso a coloca abaixo na escala evolutiva em comparação com outros seres humanos não-pretos. Destarte, a declaração afirma que negros não são humanos, mas animais.

A partir desse pressuposto, a semelhança sugerida revela uma associação da negritude com o sujo, o selvagem, o primitivo, desvelando o imaginário da branquitude sobre a suposta inferioridade das pessoas negras. Tal associação pode, ainda, ser tomada como uma declaração política de consciência racial, por meio da qual, são estabelecidos padrões dominantes de beleza, que advogam o padrão eurocêntrico como norma, rebaixando outros padrões à primitividade. Sobre isso, Kilomba (2019) assevera

\footnotetext{
${ }^{12}$ Primata, que compartilha semelhanças físicas com um cachorro, e é típico de regiões da África. Para mais detalhes, acessar: https://escola.britannica.com.br/artigo/babu\%C3\%ADno/487776.
} 


\section{REVISTA DA ABRALIN}

A metáfora do/a "africano/a" como "macaco/a" tornou-se efetivamente real, não por ser um fato biológico, mas porque o racismo funciona através do discurso. O racismo não é biológico, mas discursivo. Ele funciona através de um regime discursivo, uma cadeia de palavras e imagens que por associação se tornam equivalentes: africano - África - selva - selvagem - primitivo - inferior - animal - macaco (2019, p. 130).

Tais considerações levam-nos a concluir que o discurso proferido pelo meme analisado aponta para uma infração ao Código Penal Brasileiro que versa sobre a injúria racial em seu artigo 140, que afirma que a ofensa à dignidade e ao decoro pode incorrer em detenção ou multa. Nesse mesmo raciocínio, trazemos à baila a Lei Federal 7716/89 (BRASIL, 1989), que versa sobre os crimes resultantes de preconceito de raça, cor, etnia, religião ou procedência nacional, aspectos de intersecção da multiplicidade sociocultural das pessoas negras.

\section{Considerações finais}

Nossas análises permitiram-nos refletir sobre os impactos profundos no campo da comunicação causados pela revolução tecnológica, que culminou em desafios aos estudos da linguagem e das ciências sociais devido às profundas alterações nas interações virtuais; assistimos à readaptação e ao (re)surgimento de gêneros discursivos, entre inúmeros artefatos culturais, nos meios digitais, como blogs, e-mails, sites, redes sociais. Como consequência desse processo transformacional, destacamos os memes verbo-imagéticos de internet (CHAGAS, 2020), que têm servido de repositórios ideológicos a serviço de forças hegemônicas consolidadas nas relações assimétricas de poder entre as estruturas sociais em que o racismo mantém, com protagonismo, o privilégio de uns em detrimento de outrem.

Constatamos que, esses memes, em sua composição multimodal, trazem à tona a necessidade de refletirmos acerca da prevalência da linguagem escrita sobre os demais recursos semióticos (JEWITT, 2014), dado que o verbal não se sobrepõe ao imagético, mas atuam em sinergia para a construção de sentido. Essa afirmação evidencia-se na manipulação de elementos retóricos tais como a exploração de cores e tons, as circunstâncias espaço-temporais representadas e a saliência dada/negada aos atores sociais representados nos memes. Todos esses elementos servem para velar ou dar visibilidade a crenças, atitudes e valores incitadas por forças hegemônicas. Outrossim, em uma análise crítica, não se pode negligenciar o contexto sócio-histórico e cultural de produção desses memes, uma vez que a linguagem e a sociedade, em relação de influência mútua, são partes indissociáveis de um todo, atendendo a propósitos e intenções possíveis (HALLIDAY, 1978; HODGE; KRESS 1988) de serem (des)veladas no todo significativo que as constituem, como nos orientam estudos em semiótica social, multimodalidade e a Análise de Discurso Crítica (FAIRCLOUGH, 2001; 2003; RESENDE; RAMALHO, 2019; VIEIRA; RESENDE, 2016).

Tais aportes teórico-metodológicos ofereceram-nos dados e métodos seminais na tentativa de desvelar significados e assimetrias de poder em quatro amostras dos Memes Nego, que se pretendem 


\section{REVISTA DA ABRALIN}

"jocosos". Feitas essas considerações, objetivamos aqui refletir sobre o racismo (des)velado nesses memes na perspectiva do significado representacional e da representação dos atores sociais da ADC para lançar luz sobre o que, de fato, subjaz às supostas "brincadeiras" materializadas em seu todo multimodal.

No tocante à representação dos atores sociais, constatamos que o sujeito "Nego", no texto verbal, é representado de modo genérico, desconsidera suas especificidades sociais, geográficas e culturais; esse fato aponta para a necessidade de se desenvolver o senso crítico-reflexivo das/os leitoras/es em função do potencial desses memes em atuar a serviço de ideologias indiferentes à multiplicidade cultural e social, considerando todas as pessoas negras por uma visão unilateral que sugere, entre os seres humanos, só haver traços distintivos quando comparados às pessoas não-negras. Esse pensamento implica na legitimação da branquitude enquanto norma e na negritude enquanto exceção.

Evidenciamos o emprego do verbo "estar" revelando visões transitórias sobre as pessoas negras quando representadas em locais sociais supostamente exclusivos das pessoas brancas. Do mesmo modo, merecem atenção as estruturas verbais que atuam na legitimação do pensamento essencialista que naturaliza as posições sociais que as/os negras/os, presumivelmente, não podem ocupar. Tomemos como exemplos os memes "Nego tá soltinho hoje" (Figura 1) e "Nego tá pensando que é ken?" (Figura 3). Nesses exemplos, constatamos que o poder de decisão da branquitude é naturalizado e ajuda a legitimar a hegemonia do patriarcado branco eurocêntrico, destituindo mulheres brancas de poder, ao mesmo tempo em que excluem totalmente as mulheres negras de suas representações e apontam para os lugares que não podem ser ocupados por homens negros junto a mulheres brancas de estratos sociais prestigiados.

O significado representacional, ou seja, os modos particulares de enxergar o mundo e a si mesmo, revela crenças e valores atributivos ao corpo da pessoa negra, isto é, apontam para uma padronização de corpos e para a rejeição daqueles que não se encaixam nesse padrão como "Nego" que, representado ao lado da Barbie, compartilhando traços físicos e ocupando espaços elitistas, "ta pensando que é ken?". Esse raciocínio nos remete à urgência de deslegitimação do discurso dos corpos "perfeitos" ditados pelo mercado e pela mídia coadunada com a internet.

Essas reflexões se fazem ainda mais pertinentes em contextos em que as pessoas não se sentem incomodadas diante da percepção de que pessoas negras não são a maioria a ocupar lugares privilegiados como direções de instituições, âncoras de telejornais, autores de publicações científicas em revistas renomadas, cadeiras nos três poderes da administração nacional mesmo sendo elas (as pessoas negras) a maioria da população brasileira, segundo o IBGE. Percebemos, com tal discussão, a urgência de reparação de dívidas históricas com grupos sociais oprimidos e explorados como as comunidades negras que, por séculos, foram traficadas e vendidas como mercadorias, sendo essa uma mazela ainda da sociedade atual como apontam organizações e instituições internacionais como a Organização das Nações Unidas (ONU).

Nossas análises nos permitiram, também, refletir sobre a animalização da pessoa negra por meio da analogia negro-macaco na Figura 4 (Nego se identifica) ao sugerir que pessoas negras identificamse com seres menos desenvolvidos sociocognitivamente. Esse meme, ao corroborar o discurso racista com elementos explícitos, aponta para a urgência de se repensar posicionamentos "jocosos" 


\section{REVISTA DA ABRALIN}

em redes sociais à revelia das leis, já que a analogia sugerida fere o Código Penal brasileiro no tocante à Lei Federal 7716/89.

As observações aqui propostas levam-nos a concluir que é assertiva a afirmação de que há racismo (des)velado nos memes Nego, já que, além de implicarem em infrações às leis, sugerem a desumanização das pessoas negras, a naturalização de sua sujeição às pessoas brancas e o reforço ao imaginário de que cabe à branquitude (com a prevalência patriarcal) ocupar espaços e posições privilegiadas na sociedade brasileira. Concluímos, ainda, que não é sensato nem socialmente ético desconsiderar as possíveis ideologias (des)veladas no todo multissemiótico desses memes, já que eles silenciam os discursos das pessoas oprimidas, excluídas e relegadas às periferias do capital, pois é por meio da consideração crítico-reflexiva desses discursos que podemos contribuir para a desnaturalização de visões distorcidas da sociedade, podendo, assim, fazer fraquejar as relações assimétricas de poder e causar fricções nas estruturas sociais rumo a uma paulatina, mas possível, mudança social.

\section{REFERÊNCIAS}

ALMEIDA, S. Racismo Estrutural. São Paulo: Sueli Carneiro; Editora Jandaíra, 2020, 264p.

ARRUDA, R. B. L. Gênero meme e ensino de leitura: investigando o letramento multimodal crítico de alunos de língua inglesa. Dissertação (Programa de Pós-Graduação em Linguística Aplicada do Centro de Humanidades da Universidade Federal do Ceará) - Universidade Federal do Ceará, Ceará, 2017. Disponível em:

https://siduece.uece.br/siduece/trabalhoAcademicoPublico.jsf?id=82927. Acesso em: 15 janeiro 2021.

BARROS, S. M de. Bases filosóficas da análise de discurso crítica. In: BATISTA JR, J. R. L.; SATO, D. T. B.; MELO, I. F. de. Análise de Discurso Crítica: para linguistas e não linguistas. 1 ed. São Paulo: Parábola, 2018, p. 48-77.

BAUCKHAGE, C. Insights into Internet Memes. In: Proceedings of the international AAAI conference on web and social media, [S. 1.], v. 5, n. 1, 2011. Disponível em: https://ojs.aaai.org/index.php/ICWSM/article/view/14097. Acesso em: 11 março 2021.

BAZERMAN, C. Gêneros, Agência e Escrita. São Paulo: Cortez, 2006.

BRASIL, Presidência da República. Casa Civil, 1989. Disponível em:

http://www.planalto.gov.br/ccivil_03/leis/17716.htm. Acesso em: 15 março 2021.

CHAGAS, V. (Org.). A cultura dos memes: aspectos sociológicos e dimensões políticas de um fenômeno do mundo digital. Salvador: EDUFBA, 2020. 544p.

FAIRCLOUGH, N. Analysing discourse: textual analysis for social research. London: Routledge, 2003.

FAIRCLOUGH, N. Discurso e mudança social. Coord. Trad. Izabel Magalhães. 2. ed. Brasília: Editora Universidade de Brasília, 2001; 2019. 338p.

GOUVEIA, C. A. M. Texto e gramática: uma introdução à Linguística Sistémico Funcional. Matraga - Revista do Programa de Pós-Graduação em Letras da UERJ, [S.l.], v. 16, n. 24, jun. 2009. ISSN 2446-6905. Disponível em: https://www.e publicacoes.uerj.br/index.php/matraga/article/view/27795. Acesso em: 5 fevereiro 2021. 


\section{REVISTA DA ABRALIN}

HALLIDAY, M. A. K. Language as a Social Semiotic. London: Edward Arnold, 1978.

HODGE, R.; KRESS, G. Social Semiotics. In: Social semiotics. Ithaca, N. Y.: Cornell University Press, 1988, p. 1-12.

JEWITT, C. An introduction to multimodality. In: The Routledge Handbook of Multimodal Analysis. 2nd ed., London/New York: Routledge, 2014, p. 15-30.

KILOMBA, G. Memórias da plantação: episódios de racismo cotidiano. Rio de Janeiro: Cobogó, 2019, 248p.

LIMA-NETO, V. de. Meme é gênero? Questionamentos sobre o estatuto genérico do meme. Trab. linguist. apl., Campinas, v. 59, n. 3, p. 2246-2277, Set. 2020 . Disponível em:

http://www.scielo.br/scielo.php?script=sci_arttext\&pid=S0103-18132020000302246\&lng=en\&nrm=iso. Acesso em: 15 maio 2021.

MARTINS, F. F. G. A multimodalidade no livro didático e o letramento multimodal de alunos de inglês do ensino médio da escola pública. Dissertação (Programa de Pós-Graduação em Linguística Aplicada da Universidade Estadual do Ceará) - Universidade Estadual do Ceará, 2018. Disponível em: http://www.uece.br/posla/wpcontent/uploads/sites/53/2019/11/DISSERTAC\%CC\%A7A\%CC\%83O_FRANCISCO-FABRICIO-GARCIAMARTINS.pdf. Acesso em: 06 abril 2021.

NASCIMENTO, C. F. S. do; GABRIEL, G. A; SOUZA JÚNIOR, H. F. de; MACIEL, I. C. da S. Poder. In: IRINEU, L. M; PEREIRA, A. dos S; SILVA, A. de P. N; SANTANA, A. L. dos S; LIMA, F. H. R. de; SANTOS, S. F. dos (orgs.). Análise de Discurso Crítica: conceitos-chave. 1 ed. Campinas, SP: Pontes Editores, 2020, pp. 45-63.

PEREIRA, A. da S.; TEIXEIRA, L. M. S.; PEREIRA, R. S. Discurso In: IRINEU, L. M; PEREIRA, A. dos S; SILVA, A. de P. N; SANTANA, A. L. dos S; LIMA, F. H. R. de; SANTOS, S. F. dos (orgs.). Análise de Discurso Crítica: conceitos-chave. 1 ed. Campinas, SP: Pontes Editores, 2020, pp. 25-44.

PEREIRA A. dos S; SILVA, A. de P. N; SANTANA, A. L. dos S; LIMA, F. H. R. de; IRINEU, L. M; SANTOS, S. F. dos Análise de discurso crítica: os porquês. In: IRINEU, L. M; PEREIRA, A. dos S; SILVA, A. de P. N; SANTANA, A. L. dos S; LIMA, F. H. R. de; SANTOS, S. F. dos (orgs.). Análise de Discurso Crítica: conceitos chave. Campinas, São Paulo: Pontes Editores, 1. ed. 2020, p. 17-24.

PINHEIRO, M. S. Investigando o letramento multimodal crítico de alunos de espanhol do Ensino Médio de uma escola pública de Fortaleza-CE. 2016, Dissertação (Mestrado Acadêmico em Linguística Aplicada) - Programa de Pós-graduação em Linguística Aplicada do Centro de Humanidades da Universidade Estadual do Ceará, Fortaleza, CE, 2016. Disponível em: http://www.uece.br/posla/wpcontent/uploads/sites/53/2019/11/MICHELLE-SOARES_DISSERTAC\%CC\%A7A\%CC\%83O.pdf. Acesso em: 20 dezembro 2020.

RAMALHO, V. C. V. S. Constituição da análise de discurso crítica: um percurso teórico - metodológico. Signótica, v. 17, n. 2, p. 275-298, 6 abr. 2005. Disponível em: https://www.revistas.ufg.br/sig/article/view/3731/3486. Acesso em 02 maio 2021.

RESENDE, V. de M.; RAMALHO, V. Análise de Discurso Crítica. São Paulo: Contexto, 2 ed. 2019.

SANTAELLA, L. As Linguagens como antídotos ao midiacentrismo. MATRIZes, [S. 1.], v. 1, n. 1, p. 75-97, 2007. DOI: 10.11606/issn.1982 8160.v1ilp75-97. Disponível em: https://www.revistas.usp.br/matrizes/article/view/38178. Acesso em: 10 janeiro 2021.

SILVA, H. F. da. Definições sobre branquitude. Geledés: Artigos e reflexões, 2011. Disponível em: https://www.geledes.org.br/definicoes-sobre-branquitude/. Acesso em: 15 maio 2021. 


\section{REVISTA DA ABRALIN}

SOUZA JÚNIOR. J. de. O lado 'nego' dos memes da internet: relações entre letramento visual e a construção do negro no discurso online. Cadernos de Linguagem e Sociedade, [S. 1.], v. 17, n. 2, p. 99-121, 2016. DOI:

10.26512/les.v17i2.4012. Disponível em: https://periodicos.unb.br/index.php/les/article/view/4012. Acesso em: 15 maio 2021.

VIEIRA, J. A.; MACEDO, D. S. Conceitos-chave em análise de discurso crítica. In: BATISTA JR, J. R. L.; SATO, D. T. B.; MELO, I. F. de. Análise de Discurso Crítica: para linguistas e não linguistas. 1 ed. São Paulo: Parábola, 2018, p. 48-77.

VIEIRA, V.; RESENDE, V. de M. Análise de Discurso (para a) Crítica: o texto como material de pesquisa. 2 ed. Campinas: Pontes Editores, 2016. 